\title{
BMJ Open Does Telemedical Support of First Responders Improve Guideline Adherence in an Offshore Emergency Scenario? A Simulator-Based Prospective Study
}

To cite: Landgraf $P$, Spies $\mathrm{C}$ Lawatscheck $\mathrm{R}$, et al. Does Telemedical Support of First Responders Improve Guideline Adherence in an Offshore Emergency Scenario? A Simulator-Based Prospective Study. BMJ Open 2019;9:e027563. doi:10.1136/ bmjopen-2018-027563

- Prepublication history and additional material for this paper are available online. To view these files, please visit the journal online (http://dx.doi org/10.1136/bmjopen-2018027563).

Other parts of the results of the 'SOS - Sea and Offshore Safety' project funded by the Federal Ministry for the Environment, Nature Conservation, Building and Nuclear Safety (BMUB), funding code BMU-41V6169, have been presented at: RAVE Konsortial meeting 2012 Hamburg (RL), RAVE Conference 2012 Bremerhaven (RL), renewable UK 2013 Sheffield (RL), Rechts symposium 2013 Hamburg (TS), DIVI Workshop 2013 Hamburg (RL). This workin progress has been discussed at GMDS annual conference 2017 (PL) and conhlT2018 (PL).

Received 13 November 2018

Revised 24 May 2019

Accepted 17 July 2019

Check for updates

(C) Author(s) (or their employer(s)) 2019. Re-use permitted under CC BY-NC. No commercial re-use. See rights and permissions. Published by BMJ.

For numbered affiliations see end of article.

Correspondence to

Dr Torsten Schröder;

torsten.schroeder@charite.de

\section{Philipp Landgraf, ${ }^{\oplus 1}$ Claudia Spies, ${ }^{1}$ Robert Lawatscheck, ${ }^{1,2}$ Maria Luz, ${ }^{3}$ Klaus-Dieter Wernecke, ${ }^{4}$ Torsten Schröder ${ }^{1}$}

\section{ABSTRACT}

Objective To investigate, in a simulator-based prospective study, whether telemedical support improves quality of emergency first response (performance) by medical nonprofessionals to being non-inferior to medical professionals. Setting In a simulated offshore wind power plant, duos (teams) of offshore engineers and teams of paramedics conducted the primary survey of a simulated patient. Participants 38 offshore engineers and 34 paramedics were recruited by the general email invitation.

Intervention Teams (randomised by lot) were supported by transmission technology and a remote emergency physician in Berlin.

Outcome measures From video recordings, performance (17 item checklist) and required time (up to $15 \mathrm{~min}$ ) were quantified by expert rating for analysis. Differences were analysed using two-sided exact Mann-Whitney $\mathrm{U}$ tests for independent measures, non-inferiority was analysed using Schuirmann one-sided test. The significance level of $5 \%$ was Holm-Bonferroni adjusted in each family of pairwise comparisons.

Results Nine teams of engineers with, nine without, nine teams of paramedics with and eight without support completed the task. Two experts quantified endpoints, insights into rater dependence were gained. Supported engineers outperformed unsupported engineers $(p<0.01)$, insufficient evidence was found for paramedics $(\mathrm{p}=0.11)$. Without support, paramedics outperformed engineers $(p<0.01)$. Supported engineers' performance was noninferior (at one item margin) to that by unsupported paramedics $(p=0.03)$. Supported groups were slower than unsupported groups $(p<0.01)$.

Conclusions First response to medical emergencies in offshore wind farms with substantially delayed professional care may be improved by telemedical support. Future work should test our result during additional scenarios and explore interdisciplinary and ecosystem aspects of this support. Trial registration number DRKS00014372

\section{INTRODUCTION}

\section{Context}

During construction and maintenance of offshore wind farms, medical support has to be
Strengths and limitations of this study

- This telemedical intervention applied in a simulated offshore emergency scenario was feasible.

- The chosen methods were adequate in resolving the hypothesised effects. Despite improved validity and reliability, generalisability of our findings may be limited.

- Telemedical support improved layman performance to being non-inferior to that by paramedics with relevance for current medical service challenges.

available to teams as small as three maintenance engineers. ${ }^{1}$ Emergency rescue was performed in 70 of 319 medical support cases in four German offshore wind farms between 2008 and 2012. Most rescues were triggered by accidents and respiratory or intestinal illness. ${ }^{2}$ Medical response teams may take more than $90 \mathrm{~min}$ to arrive due to distance (up to $200 \mathrm{~km}$ ), weather and structural inaccessibility. ${ }^{13}$ Delay of necessary treatment or rescue due to misjudgement may plausibly result in lasting damage or loss of life for patients and psychological trauma for first responders or unnecessary risk and costs for the rescue teams. ${ }^{4}$ Furthermore, in both scenarios 'rescue required and arriving quickly' and 'low urgency, relief under way', immediate assessment and treatment may be warranted ${ }^{25}$ and reduce on-scene time of medical services. ${ }^{6}$

\section{Telemedicine}

Various teleconsultations between medical professionals were reported in recent years to benefit quality of care. ${ }^{7-11}$

Telemedical support may already be provided by the medical professionals to non-professionals off shore, ${ }^{12}$ but the effects on quality of care by non-professionals are only clear for cardiopulmonary 
resuscitation. ${ }^{13} 14$ We hypothesised that real-time teleconsultations for non-professional first responders in an emergency scenario improves guideline adherence and time to treatment surrogative of quality of care. Under the assumption of this scenario being commonplace for professionals, we used this group's performance as a benchmark.

\section{METHODS AND MATERIALS \\ Summary}

In a simulated scenario, two participants were to survey vital data of a simulated polytraumatised colleague. The intervention groups (half of the non-professional and professional teams) had a telemedically enabled vital data monitoring unit (corpuls-3 with corpuls.web, GS Elektromedizinische Geräte G. Stemple, Kaufering, Germany) and were supported by a remote physician by means of a communication device (Frontline Communicator, MDAI mobile solutions, Wolfratshausen, Germany). Guideline adherence in terms of the number of correctly performed checklist items and, as indicative of time prior to treatment, required time for the initial survey were adjudicated using video recordings of the scenario.

\section{Patient and public involvement}

Offshore engineers were involved in the study design, scenario validation, recruited as participants, debriefed and interviewed about their participation and for feedback on the study design and telemedical intervention.

\section{Subject pool}

To compare the effect of the intervention on groups with different medical expertise, after receiving positive ethics committee vote (Ethikkommission-Ethikausschuss 1 am Campus Charité Mitte, EA1/181/13), offshore maintenance engineers working with the industrial partner (EWE Energie AG, Oldenburg, Germany) and paramedics working with the Berlin Fire Department were recruited through a general email invitation. Responders were eligible for participation if they gave personal informed consent to participate, confirmed they were healthy, fit, proficient in German, understood that they would be videotaped and evaluated. The engineers were paired up into teams with at least one member with offshore emergency response officer (50 hours) or higher medical training. These teams were randomised by lot into intervention and control groups. The paramedics were likewise paired up into teams and the teams likewise randomised by lot into intervention and control groups. All participants were familiarised with devices (particularly simulators) to be used ahead of time.

\section{Sample size and power calculations}

Without knowledge of the feasibility and acceptability of the intervention, design, procedures, measurability of effects and estimation of precision, the calculation of necessary sample size was not possible. The number of participants was, therefore, generally justified by practical needs of the project, acknowledging the interindividual and intraindividual variability as well as psychosociological processes under described circumstances. From the data this exploration yielded, the post hoc power was calculated (see online supplementary A) to advise future research.

\section{Experimental set-up}

The paramedics participated in a seminar room at Charité in Berlin and the engineers in a seminar room in Oldenburg.

A standard emergency case ${ }^{15}$ was available within the simulation area. It contained among other items gloves, stethoscope, blood pressure cuff and diagnostic penlight.

As shown in figures 1 and 2, supported teams were additionally given a monitoring device to survey noninvasive blood pressure, blood oxygen saturation and ECG (corpuls-3) and a two-way audio and one-way video transmission device (Frontline Communicator). Both devices connected wirelessly to the remote physician in an office at Charité. The remote physician had at his disposal a checklist containing: the items in table 1, reminders to advise the teams to use gloves and advice on finding non-invasive blood pressure cuff and stethoscope inside the emergency case.

Five anaesthesiologists with expertise in prehospital emergency medicine and in conducting simulation workshops volunteered as remote physicians at Charité. They telemedically supported intervention groups.

A clothed human patient simulator (Emergency Care Simulator, CAE Healthcare, Mainz, Germany) lay on the floor inside the simulation area. Two of the authors took turns operating the simulator, using a microphone to speak as though from the simulator's mouth. This simulator had controllable eye lids, interfaced with arbitrary peripheral oxygen saturation $\left(\mathrm{SpO}_{2}\right)$ clips, emulated 5 channel ECG, pupillary light reflex, radial and carotid pulses, chest excursion and breathing sounds. A phantom fracture was fixed to its arm and a phantom burn to its lower leg.

Two perspectives on the simulation area and one on the remote physician were video recorded for adjudication by two experts in prehospital emergency medicine.

\section{Scenario: Retrieve vital data}

The team was described to be on maintenance mission in a specific offshore wind park, inside a power plant marked by the simulation area. A colleague among the team of three (the human patient simulator) had fallen from $4 \mathrm{~m}$ height. To increase immersion, the simulator kept moaning and calling for pain relief.

Each team of two participants was given the task of only collecting vital signs, patient history and 'anything that might help a medic'.

\section{Scenario validation}

The representative scenario designers (two of the authors) conducted unstructured literature reviews on most common emergencies and causes of death in offshore settings, unstructuredly interviewed offshore maintenance 


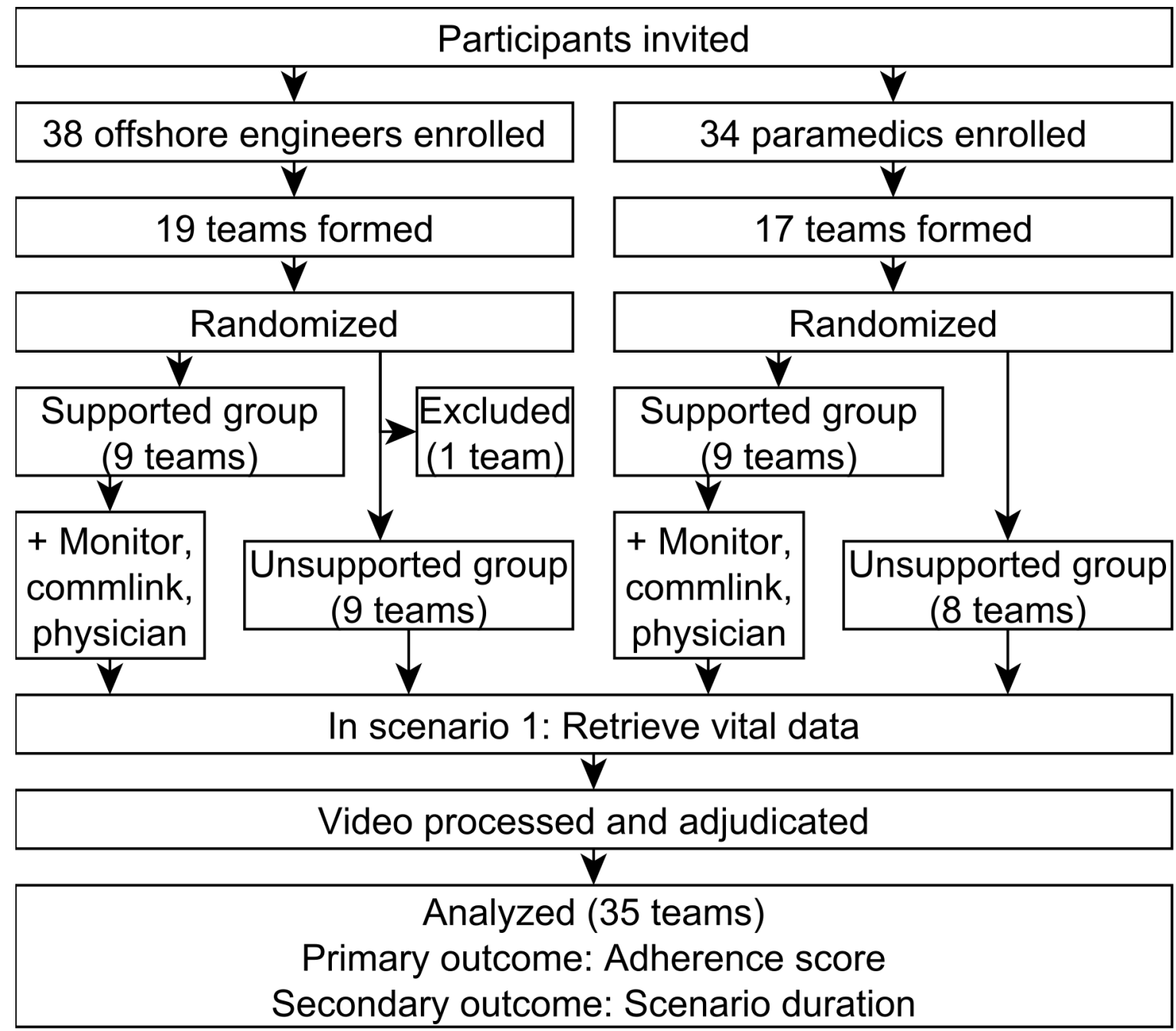

Figure 1 Flow diagram of the simulator study. Randomisation into groups, half of them supported by a remote physician via a telemedically enabled monitoring unit and bidirectional commlink. One team dropped out due to illness.

engineers and wind power plant operators and discussed typical emergencies, ${ }^{2}$ response and treatment with the typical rescuers. These typical rescuers were paramedics working at the offshore rescue headquarters and physicians working at the receiving hospital department. Moreover, both of them visited an onshore wind power plant, attained helicopter hoist certification and survival at sea certification and visited an offshore wind power plant by helicopter hoist.

All offshore wind power plant construction company representatives at the consortium meetings informally confirmed the validity of the experimental set-up.

\section{Supervision}

Every participant and remote physician was given a briefing in writing and a 2-hour introduction to the technology to be used. Additionally, a moderator recounted for each team the scenario and task using scripted sentences at the beginning of the scenario. Any side-tracking due to problems with the telemedical equipment was dealt with in technical timeouts. Any action beyond the given task was halted to be performed in a later scenario.

\section{Data acquisition}

A checklist (see table 1) of correct-incorrect-unclear items was preliminarily designed to operationalise adherence to European Resuscitation Council (ERC) guidelines ${ }^{16}$ by two anaesthesiologists (two of the authors). Notably, the Airway, Breathing, Circulation, Disability, Exposure approach therein is applicable for all emergencies. A total of 14 out of 17 items ( $82 \%$ ) were asked directly after a team claimed to have collected all relevant information. Supported teams were to confer with their remote physician, the combined knowledge being the endpoint. Perspective-synchronised recordings of the scenario, remote physician and questioning constituted the data for review. One of the authors and an independent peer adjudicated all scenarios, classifying items as correctly/incorrectly performed or unclear and measured scenario duration without timeouts.

\section{Metrics validation}

In operationalising the ERC guidelines, all applicable Good ReseArch for Comparative Effectiveness principles (graceprinciples.org) were considered. The checklist reliability 


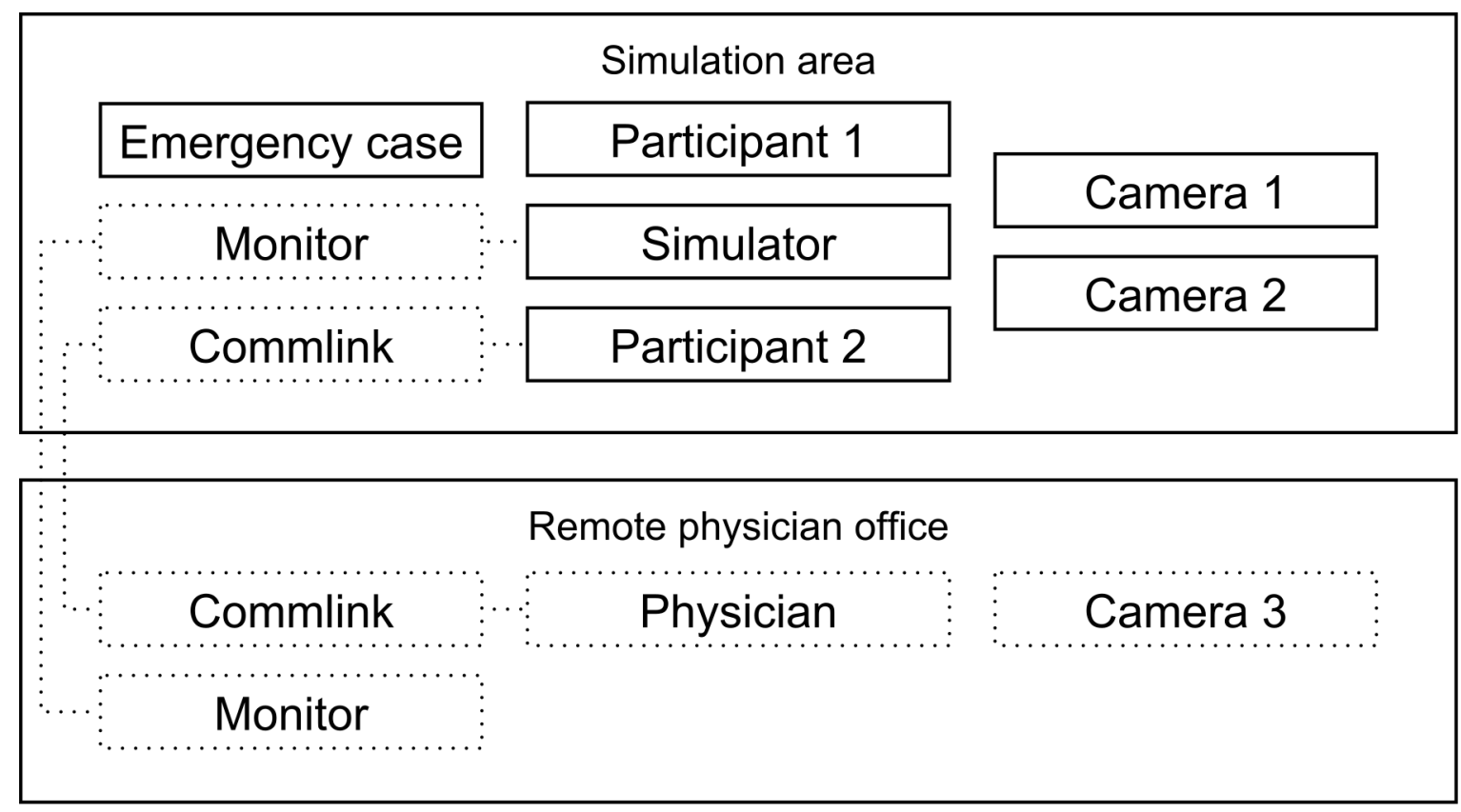

\section{Control}

Intervention

Figure 2 Schematic experimental set-up for control (continuous line) and intervention groups (dotted line): participants and simulator in the simulation area were video recorded from two angles, the remote physician from one angle. All groups had a standard emergency case but intervention groups additionally had audio-video communication (commlink) with and vital data transmission (monitor) to a remote physician.

and validity were probed in two test simulations. No efforts were undertaken to validate the duration metric.

Under the assumption that professional first responders adhere to guidelines well and deliver high quality of care, the checklist item scoring range is calibrated to resolve group differences. Differences in required time are expected to be clearly resolved and will not be scaled.

\section{Data validation}

Inter-rater reliability was estimated using average intraclass correlation coefficients (ICC) in a two-way random-effects model for absolute agreement (ICC $(2,2)), 95 \%$ CIs are reported $([\cdot, \cdot])$. Quantile-quantile plots and minima in proportionate positive inter-rater agreement were explored. Please see online supplementary B for details.

\section{Data analysis}

Average rater rating of number of items correctly performed per team (itemised performance) was analysed with two-sided exact Mann-Whitney $\mathrm{U}$ test for independent measures (2sU) comparing

1. Supported against unsupported engineers and supported against unsupported paramedics.

2. Unsupported engineers against unsupported paramedics.

3. Supported engineers against supported paramedics.

4. Supported engineers against unsupported paramedics. Additionally,

5. Non-inferiority of the performance by supported engineers compared with unsupported paramedics was analysed using Schuirmann one-sided test at $5 \%$ significance with a one-item margin (SOST).

Average rater measurement of scenario duration was evaluated using 2sU comparing

6. Supported against unsupported engineers and supported against unsupported paramedics.

7. Unsupported engineers against unsupported paramedics.

8. Supported engineers against supported paramedics.

9. Supported engineers against unsupported paramedics. Finally,

10. The number of teams per group who, by average rating, correctly performed each item was analysed descriptively.

Medians (Md), $95 \%$ CIs of Md $([\cdot, \cdot])$, absolute z-value $(z), 1-/ 2$-sided exact significance (p) and effect size (d) are reported.

The significance level of $5 \%$ was Holm-Bonferroni adjusted in each family of pairwise comparisons: Performance, non-inferiority and duration. Adjusted significance is denoted $(*)$.

All tests were conducted using SPSS V.24 (IBM) where possible and EquivTest (StatCon, Witzenhausen, Germany) otherwise.

\section{RESULTS}

After drop-outs due to illness, 36 off-shore maintenance engineers (medical non-professionals, 32 male and 4 
Table 1 Checklist of itemised performance quality attributes as used by the remote physician and for evaluation per team and scenario

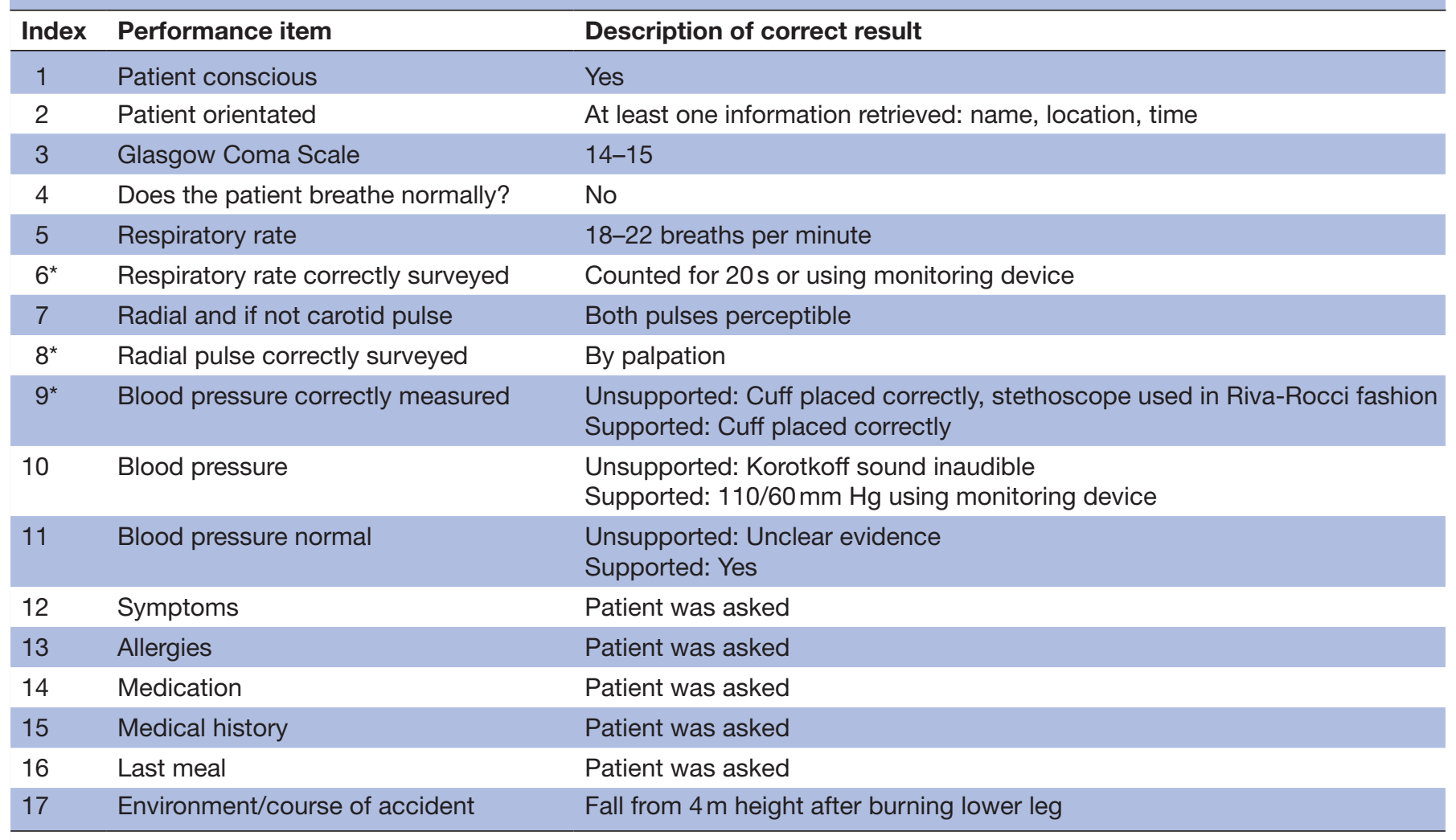

They are ordered according to the sequence the authors would perform them in.

*Item not asked at the end of the scenario but observed in the video material.

female, aged $\mathrm{Md}=41, \mathrm{IQR}=[32,47])$ and 34 paramedics (medical professionals, 30 male and 4 female, aged $\mathrm{Md}=$ $36, \mathrm{IQR}=[27,45])$ participated in the study. All engineers had taken at least first aid (16hours) training refreshed Md $=12, \mathrm{IQR}=[9,16]$ months prior. All paramedics had at least 2 years of work experience and regular first aid training. Figure 1 illustrates the study design with final sample sizes.

Inter-rater reliability was estimated for performance per team $\operatorname{ICC}_{\mathrm{ppt}}(2,2)=0.71[-0.10,0.90]$, required time per team $\operatorname{ICC}_{\mathrm{tpt}}(2,2)=0.99[0.98,0.99]$ and performance per item $\operatorname{ICC}_{\mathrm{ppi}}(2,2)=0.66[0.52,0.74]$.

Scaling the item-score relationship to $100 \%$ (a difference of one item translates to a difference by one performance score) resolves group differences sufficiently.

Effects of both experimental conditions on performance rating and time in minutes required to complete the scenario (average across raters) are condensed in figure 3 and shown in figure 4 .

a. Supported outperformed unsupported participants. This intervention effect was statistically significant among non-professionals but not among professionals.

b. Performance differences due to medical expertise is statistically significant in unsupported groups; professionals correctly performed twice as many items as non-professionals. c. With telemedical support, this difference was not statistically significant.

d. No statistical evidence was found that unsupported professionals outperformed supported non-professionals.

e. Moreover, SOST rejects the null hypothesis of non-equivalence. Thus, non-inferiority of supported non-professionals' to unsupported professionals' performance within the specified equivalence bounds (difference of means less than or equal one item correctly performed) can be claimed.

f. Participants who were supported required significantly more time compared with unsupported participants.

g. Without telemedical support, no statistical evidence was found for either groupbeing faster.

h. In supported groups, non-professionals took more time.

i. Supported non-professionals required more time than unsupported professionals.

j. Non-professionals without support likely surveyed consciousness (item 1), pulse rate (8), symptoms (12) and environment (17) correctly (see figure 5). Professionals in the intervention group more often correctly surveyed respiration (4-6) and food intake (16) but less often manually surveyed radial pulse (7-8). 


\begin{tabular}{|c|c|c|c|c|c|c|c|c|c|}
\hline & \multirow{2}{*}{ Ref. } & \multicolumn{2}{|c|}{ unsupported } & \multicolumn{2}{|c|}{ supported } & \multirow{2}{*}{ Test } & \multirow{2}{*}{ Statistic } & \multirow{2}{*}{$\begin{array}{l}\text { Effect } \\
\text { Size }\end{array}$} & \multirow{2}{*}{$p$-value } \\
\hline & & non- $(n=9)$ & prof. $(n=8)$ & non- $(n=9)$ & prof. $(n=9)$ & & & & \\
\hline & & $4.50[3.50,7.50]$ & $11.75[9.25,12.50]$ & $11.50[10.50,13.50]$ & $13.00[12.00,14.00]$ & & & & \\
\hline & \multirow{2}{*}{ a } & $X$ & & $X$ & & $2 \mathrm{sU}$ & 3.59 & 3.13 & $<.01 *$ \\
\hline & & & $X$ & & $X$ & $2 \mathrm{sU}$ & 1.65 & .86 & .11 \\
\hline & $\mathrm{b}$ & $X$ & $X$ & & & $2 \mathrm{sU}$ & 3.09 & 2.25 & $<.01 *$ \\
\hline \multirow{2}{*}{ 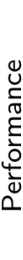 } & c & & & $X$ & $X$ & $2 \mathrm{sU}$ & 1.11 & .54 & .29 \\
\hline & $\mathrm{d}$ & & $X$ & $X$ & & $2 \mathrm{sU}$ & .78 & .38 & .46 \\
\hline & e & & $X$ & $X$ & & SOST & 1.98 & (a) & $.03 *$ \\
\hline \multirow[t]{2}{*}{ 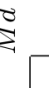 } & & $6.55[4.38,8.55]$ & $4.38[3.92,7.08]$ & $11.87[9.25,13.05]$ & $7.62[7.05,9.50]$ & & & & \\
\hline & $f$ & $X$ & & $X$ & & $2 \mathrm{sU}$ & 2.96 & 1.95 & $<.01 *$ \\
\hline & 1 & & $X$ & & $X$ & $2 \mathrm{sU}$ & 2.60 & 1.62 & $<.01 *$ \\
\hline & g & $X$ & $X$ & & & $2 \mathrm{sU}$ & 1.44 & .75 & .16 \\
\hline & $\mathrm{h}$ & & & $X$ & $X$ & $2 \mathrm{sU}$ & 2.43 & 1.40 & $.01 *$ \\
\hline & $\mathrm{i}$ & & $X$ & $X$ & & $2 \mathrm{sU}$ & 3.47 & 3.10 & $<.01 *$ \\
\hline
\end{tabular}

Figure 3 Median (Md) performance ratings and required time in minutes with $95 \% \mathrm{Cls}$ of $\mathrm{Md}$ with results for performance rating tests $A-E$ and required time tests $F-I$ rounded to two decimal places. $X$ indicates tested pairs of groups (size indicated by $n$ ) of unsupported (control) and supported (intervention) engineers (medical non-professionals) and paramedics (medical professionals). Tests are two-sided exact Mann-Whitney $U$ test for independent measures (2sU) or Schuirmann one-sided test at $5 \%$ significance with a one-item margin (SOST). Typical denotation of the statistic of 2sU tests is z, that of SOST is t and typical denotation of effect size is $\mathrm{d}$. Adjusted significance ( $p$ value) is indicated by *. (a) Note that SOST tests for an effect being smaller than the margin.

\section{DISCUSSION}

In a crucial information collection phase of emergency care, the telemedically supported non-professionals performed more items correctly than unsupported non-professionals (see figure 4). The authors hypothesise that, because the scenario was subjectively immersive and the live video feed subjectively very helpful, this effect would also occur if real medical emergencies were similarly supported. Supported non-professionals' performance was non-inferior to that by unsupported professionals. As can be seen in figure 4, supported non-professionals performed slightly more items correctly than unsupported professionals. This could be life-saving in environments of no or substantially delayed professional medical response. ${ }^{17}$

Among professionals, less impact on performance was observed (see figure 4). This confirms our assumption of this phase of emergency care being commonplace.

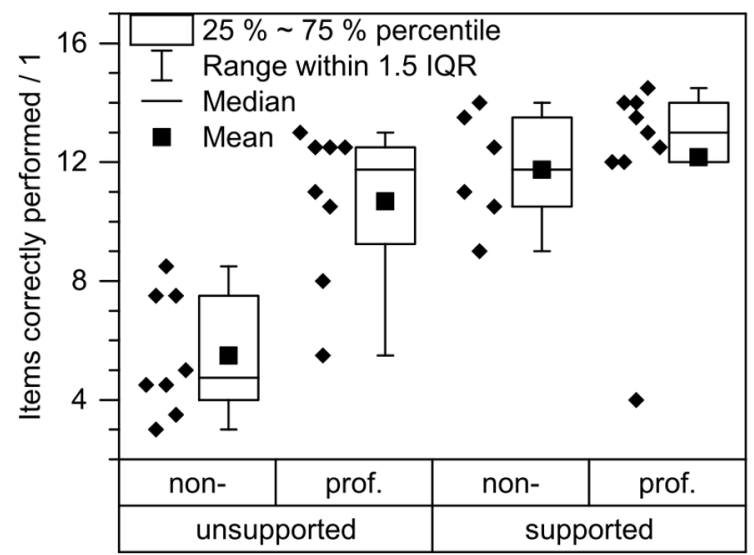

The performance of additional items required additional time (see figure 4). While in onshore scenarios (eg, cardiac arrest in King Country, Washington, USA excluding Seattle) professional help would probably have arrived during the scenario duration, ${ }^{18}$ helicopter emergency medical services in rural scenarios would not $\left(\sim 30\right.$ min to arrival). ${ }^{19} 20$ In remote cases, the required time does not necessarily delay rescue. On the contrary, more accurate first response could expedite triggering the appropriate rescue chain, which is independently associated with greater survival ${ }^{21}$ and plausibly reduce on-scene time. ${ }^{6}$ During a support gap pertaining to the remoteness and accessibility of offshore wind farms, even slow information collection may significantly improve outcome if it is reliable and available to alert and involve relevant specialists especially before arrival of a rescue team. ${ }^{822} 23$ Non-professionals need to and, as our results

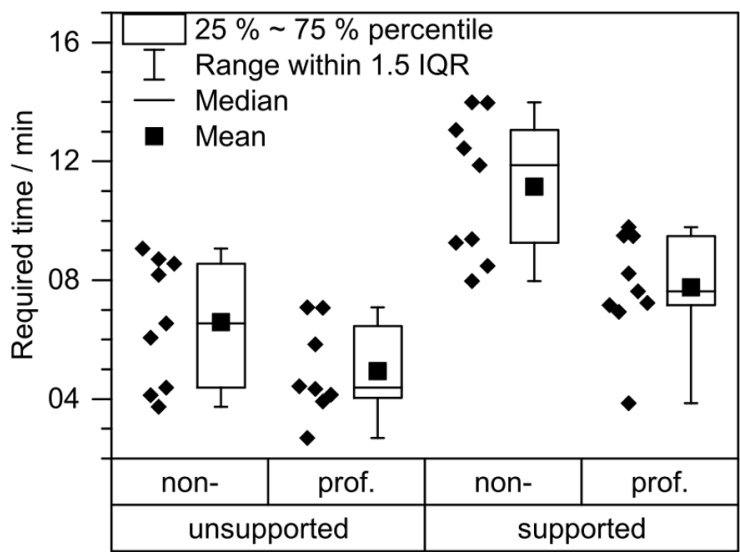

Figure 4 Itemised performance rating and time required by a team to finish the scenario: unsupported (control) and telemedically supported (intervention) groups with breakdown into medical non-professionals (non-) and professionals (prof.). 
Number of teams in a group who correctly performed an item / 1
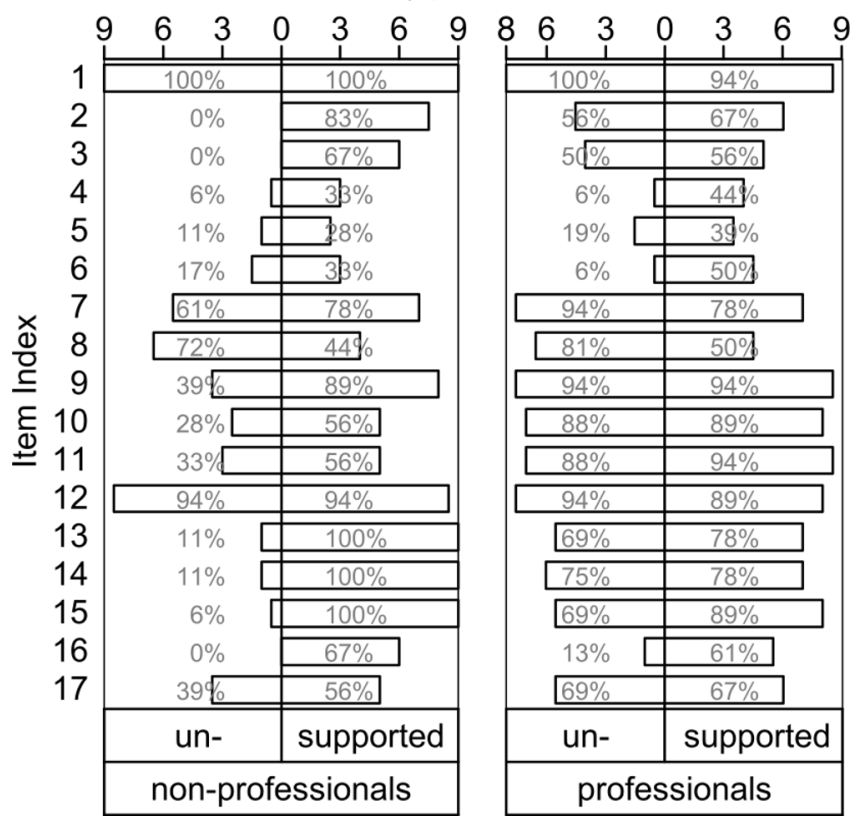

Figure 5 Distribution of number of teams who correctly performed an item (description in table 1) averaged across raters. Medical non-professionals versus professionals with breakdown into unsupported (control) and telemedically supported (intervention) groups.

show, could be able to bridge this gap with telemedical support.

Neither participants nor remote physicians were experienced in telemedicine. The authors suppose, after reviewing frequent misunderstandings, that training and hands-on experience would optimise communication, reducing the increase in required time.

The observed benefit in information completeness (see figure 5) may be crucial. ${ }^{24}$ In agreement, Rörtgen $e t$ $a t^{25}$ found significantly increased completeness only of survey of symptoms, allergies and medication from the SAMPLE mnemonic among physician-paramedic teams (EMS teams) in supported groups. The same research group reported in Skorning et $a l^{26}$ that EMS teams with telemedical support significantly outperformed those without support in surveying allergies from the SAMPLE mnemonic. Moreover, analgosedation prior to cardioversion, synchronicity of shocks and adequate medication for intubation were improved by telemedical support. Cathlabs were significantly more often and trauma centres more quickly informed.

Unsupported non-professionals correctly surveyed consciousness, heart rate, symptoms and environment correctly (see figure 5). This may plausibly be due to the first aid or emergency response officer course all but two non-professionals had taken at most 2 years $(\mathrm{Md}=12, \mathrm{IQR}$ $=[9,16]$ months) prior. With telemedical support, surveys by non-professionals and professionals were more complete excepting only the notably low score in breathing related items 4-6 and item 8 (radial pulse palpated). In agreement, real-time provider feedback alone during surgery seems to improve checklist compliance. ${ }^{27}$

The low scores in breathing related items 4-6 may in part be due to raters' different interpretation of deviation from actually simulated vital data and from guidelines. These different interpretations manifest in correlation coefficients for performance per item being lower than for performance or time per team and are therefore discussed in depth in online supplementary B. The authors hypothesise that remaining room for improvement is a compound need-for-training and remote physician effect requiring a larger sample to be explored.

Item 8 on radial pulse palpation having been rated less often correctly performed for supported groups seems to stem from only one rater judging the correct result (pulse rate) integral to the correct measurement (see online supplementary B). However, with support, most teams used the networked monitoring device to attain a pulse rate result.

Our results imply that telemedically supporting non-professionals could be more than a fallback option: It could viably expand the continuum of care beyond the reach of specialised staff.

\section{Limitations}

Like Branzetti et $a l^{28}$ we designed a checklist ourselves. Unavoidably, our own choice of scenario, metric and data validation efforts may be biassed.

Results concerning offshore engineers may not be representative for non-professionals in general; offshore engineers are highly trained and relatively proficient in emergency first response, following technical instructions and manual tasks.

We did not isolate the effect of variations in the intervention design (such as only monitoring device vs only communication device vs both, different remote physicians or different communication strategies) for lack of sample size. We know only that a visual reminder alone would be unlikely to achieve the observed effect on quality of care. The impact of visual reminders on guideline adherence (quality of care), displayed on a phone during cardiac arrest first response, was not statistically significant while the impact by medical expertise was. ${ }^{29}$ An audio-video instruction on a phone or big screen seems to improve at least some aspects of resuscitation performance ${ }^{30-32}$ and trained laymen phone support outside of emergencies seems to improve only some risk behaviour. ${ }^{33}$

Moreover, we resolved neither intrateam effects, nor team versus individual performance.

The non-inferiority margin of one item was chosen after the scenarios had been conducted but before scenario recordings had been processed based on medical expertise. It should have been selected prior to possible bias by trial experience, which had not been considered.

The simulator operator, facilitator, remote physician and video adjudicator roles were assigned based on availability, not randomisation. No one person could have taken on more than one of these roles at a time and bias in the results 
was minimised by averaging with an independent review (see online supplementary B on data validation). Random assignment of independent persons without any rotation into one of the other roles would have been preferable but was not feasible in our hospital context.

Remote physician unfamiliarity with an uncommon scenario would have been realistic. ${ }^{34}$ On the other hand, our scenario was common (as the small impact of our intervention on medical professionals confirms). Moreover, detailed checklists for both common and less common scenarios would also be realistic.

In Skorning et $a l,{ }^{26}$ 'two faculty investigators using (...) scoring items (...) had to reach common decisions'. In contrast, we used ratings by one of the authors and an independent peer to probe reliability, learn about $\mathrm{df}$ and reduce bias (see online supplementary B). The quality of care under investigation, however, is distorted by the simulation setting, the scenario artificiality, the recording modality and the projection onto items. During the transformation from input (care) to output (scores) via video recording and adjudication, fit between video and item confounded the relationship between quality of care and score. The choice of experts with similar backgrounds plausibly reduced but failed to eliminate this factor fully (see online supplementary B). Training experts to a level of agreement first, as done by Branzetti et $a l^{28}$ seems to be a sensible effort at reduction of room for interpretation.

The scenario has been designed as a compromise between investigative goals and safety as is known to serve training purposes well. ${ }^{28}$ The offshore boundary conditions restricted space, limited resources, fibre internet, medical devices and supplies and standard emergency case were reproduced based on first-hand observation by the scenario designers and are also reported by Stuhr et al. ${ }^{23}$ Most imaginable offshore situational conditions, such as high stress levels, cumbersome clothing, extreme weather, blood everywhere and emotional involvement, were not or not entirely reproduced, as they were expected to add inhomogeneous effects requiring additional power for isolation. To confirm homogeneity of immersion, the perception of the simulation environment should have been rigorously investigated but was not, because simulation of the kind employed by us has been found to be a sufficiently valid surrogate for scenarios otherwise impossible to observe consistently. 3536 Blinding was not feasible. Setting effects and expectations may have distorted the results. For the non-professionals who are luckily unlikely to have ever encountered a polytraumatised patient but also for the professionals who working in Berlin are unlikely to have first-hand experience of an offshore wind power plant.

\section{Perspectives}

The chosen offshore scenario is distinguished from more common scenarios, such as in urban environments, by magnitude of consequences of rescue decisions and of the supply gap. Performance difference in medically advanced scenarios and feasible equipment scope are relevant subsequent questions. Considering the prevalence of hypoxia prior to intubation by emergency medical services reported by Sunde $e t a l,{ }^{37}$ the disagreement as well as the imperfect scores by supported teams in breathing-related items are important findings to be investigated closely. The unsupported versus supported decision-making process in the context of risk for the patient, risk for the rescue teams and of potential health economic outcomes are of great interest. ${ }^{38}$ Particularly, first aid response rate among offshore personnel $^{40}{ }^{41}$ may be increased. The technological implementation (Such as [12] or ghc-tech.de.) and business models (Such as gmn-bremen.de.) are topics of investigation. While support of medical professionals is gaining momentum, emerging onshore telematics infrastructure, assessment and communication best practices should be adapted to offshore use cases. Effective training and guidelines for remote physicians warrant comparative analyses. With increasingly complex and invasive medical tasks, differences in immediate and latent psychological responses with or without telemedical support gain importance.

\section{CONCLUSION}

The investigated telemedical support of offshore engineers during the initial survey of a simulated emergency benefited guideline adherence and required additional time. First response to medical emergencies during construction and maintenance of offshore wind farms with substantially delayed professional care may be improved by telemedical support.

\section{Author affiliations}

${ }^{1}$ Department of Anesthesiology and Intensive Care Medicine Campus Charité Mitte and Campus Virchow-Klinikum, Charité - Universitätsmedizin Berlin, corporate member of Freie Universität Berlin, Humboldt-Universität zu Berlin, and Berlin Institute of Health, Berlin, Germany

${ }^{2}$ Global Medical Affairs, Therapy Area Cardiovascular, Bayer Pharma AG, Berlin, Germany

${ }^{3}$ Faculty of Computer Science, Otto-von-Guericke-University Magdeburg, Magdeburg, Germany

${ }^{4}$ Sophisticated Statistical Analysis GmbH, Berlin, Germany

Contributors PL, CS, RL, KDW and TS made substantial contributions to the conception and design of this work. PL, RL and TS made substantial contributions to the acquisition, PL, ML, KDW and TS to the analysis. PL, CS and TS to the interpretation of data.PL, ML and TS made substantial contributions to drafting the work. PL, CS, RL, ML, KDW and TS to revising it critically for important intellectual content. PL, CS, RL, ML, KDW and TS gave final approval of the version published. $\mathrm{PL}, \mathrm{CS}, \mathrm{RL}, \mathrm{ML}, \mathrm{KDW}$ and TS agreed to be accountable for all aspects of the work in ensuring that questions related to the accuracy or integrity of any part of the work are appropriately investigated and resolved.

Funding statement The 'SOS—Sea and Offshore Safety' project was funded solely bythe German Federal Ministry for the Environment, Nature Conservation, Building and Nuclear Safety (BMUB), funding code 0325532.

Competing interests CS was leader of the 'SOS - Sea and Offshore Safety' project and received funding BMUB 0325532 for the project. All other authors declare that they have no financial or personal relationships with other people or organizations that biased this work. None of the authors has been remunerated for work on this publication.

Patient consent for publication Not required.

Provenance and peer review Not commissioned; externally peer reviewed.

Data availability statement Data are available on reasonable request. 
Open access This is an open access article distributed in accordance with the Creative Commons Attribution Non Commercial (CC BY-NC 4.0) license, which permits others to distribute, remix, adapt, build upon this work non-commercially, and license their derivative works on different terms, provided the original work is properly cited, appropriate credit is given, any changes made indicated, and the use is non-commercial. See: http://creativecommons.org/licenses/by-nc/4.0/.

\section{REFERENCES}

1. Stuhr M, Kraus G, Weinrich N, et al. Erste Hilfe in OffshoreWindparks in deutschen Gewässern. Der Notarzt 2014;30:159-68.

2. Stuhr M, Dethleff $D$, Weinrich N, et al. Vorläufige Auswertung: Medizinische Ereignisse in Offshore-Windparks - Erste Informationen zu Unfallverletzungen und Erkrankungen. Flug u Reisemed 2015;22:14-19.

3. Stuhr M, Dethleff D, Weinrich N, et al. [Medical Emergency Preparedness in offshore wind farms: New challenges in the german north and baltic seas]. Anaesthesist 2016;65:369-79.

4. Hirshon JM, Galvagno SM, Comer A, et al. Maryland's helicopter emergency medical services experience from 2001 to 2011: system improvements and patients' outcomes. Ann Emerg Med 2016;67:332-40.

5. Spaite DW, Hu C, Bobrow BJ, et al. Association of out-of-hospital hypotension depth and duration with traumatic brain injury mortality. Ann Emerg Med 2017;70:522-30.

6. Østerås Øyvind, Heltne J-K, Vikenes B-C, et al. Factors influencing on-scene time in a rural Norwegian helicopter emergency medical service: a retrospective observational study. Scand J Trauma Resusc Emerg Med 2017;25:97.

7. Latifi R, Hadeed GJ, Rhee P, et al. Initial experiences and outcomes of telepresence in the management of trauma and emergency surgical patients. Am J Surg 2009;198:905-10.

8. Demaerschalk BM. Telemedicine or telephone consultation in patients with acute stroke. Curr Neurol Neurosci Rep 2011;11:42-51.

9. McBeth P, Crawford I, Tiruta C, et al. Help is in your pocket: the potential accuracy of smartphone- and laptop-based remotely guided resuscitative telesonography. Telemed J E Health 2013;19:924-30.

10. Brokmann JC, Rossaint R, Bergrath S, et al. [Potential and effectiveness of a telemedical rescue assistance system. Prospective observational study on implementation in emergency medicine]. Anaesthesist 2015;64:438-45.

11. Fang JL, Campbell MS, Weaver AL, et al. The impact of telemedicine on the quality of newborn resuscitation: a retrospective study. Resuscitation 2018;125:48-55.

12. Czaplik M, Bergrath S, Rossaint R, et al. Employment of telemedicine in emergency medicine. Clinical requirement analysis, system development and first test results. Methods Inf Med 2014;53:99-107.

13. Bohn A, Lang S, Wnent J, et al. Lay-rescuer-CPR and telephoneassisted-CPR shorten the resuscitation-free interval and thus improve long-time survival. An analysis of the German resuscitation registry. Resuscitation 2017;118

14. Wu Z, Panczyk M, Spaite DW, et al. Telephone cardiopulmonary resuscitation is independently associated with improved survival and improved functional outcome after out-of-hospital cardiac arrest. Resuscitation 2018;122:135-40.

15. Castan J, Paschen H-R, Wirtz S, et al. Massenanfall von Verletzten auf see in deutschen Gewässern. Anaesthesist 2012;61:618-24.

16. Perkins GD, Olasveengen TM, Maconochie I, et al. European resuscitation Council guidelines for resuscitation: 2017 update. Resuscitation 2018;123:43-50.

17. Ljunggren $\mathrm{M}$, Castrén $\mathrm{M}$, Nordberg $\mathrm{M}$, et al. The association between vital signs and mortality in a retrospective cohort study of an unselected emergency department population. Scand J Trauma Resusc Emerg Med 2016;24:21.

18. Gold LS, Fahrenbruch CE, Rea TD, et al. The relationship between time to arrival of emergency medical services (EMS) and survival from out-of-hospital ventricular fibrillation cardiac arrest. Resuscitation 2010;81:622-5.

19. Chesters A, Harris T, Hodgetts TJ, et al. Survival to discharge after cardiac arrest attended by a Doctor-Paramedic helicopter emergency medical service: an Utstein-style Multiservice review of 1085 activations. J Emerg Med 2015;49:439-47.

20. Nolan B, Tien H, Sawadsky B, et al. Comparison of helicopter emergency medical services transport types and delays on patient outcomes at two level I trauma centers. Prehosp Emerg Care 2017;21:327-33.

21. Nichol G, Cobb LA, Yin L, et al. Briefer activation time is associated with better outcomes after out-of-hospital cardiac arrest. Resuscitation 2016;107:139-44.

22. Sejersten M, Sillesen M, Hansen PR, et al. Effect on treatment delay of prehospital Teletransmission of 12-lead electrocardiogram to a cardiologist for immediate triage and direct referral of patients with ST-segment elevation acute myocardial infarction to primary percutaneous coronary intervention. Am J Cardiol 2008;101:941-6.

23. Sanchez-Ross M, Oghlakian G, Maher J, et al. The STAT-MI (STsegment analysis using wireless technology in acute myocardial infarction) trial improves outcomes. JACC Cardiovasc Interv 2011;4:222-7.

24. Nishijima DK, Gaona SD, Waechter T, et al. Out-of-Hospital Triage of Older Adults With Head Injury: A Retrospective Study of the Effect of Adding "Anticoagulation or Antiplatelet Medication Use" as a Criterion. Ann Emerg Med 2017;70:127-38.

25. Rörtgen D, Bergrath S, Rossaint R, et al. Comparison of physician staffed emergency teams with paramedic teams assisted by telemedicine--a randomized, controlled simulation study. Resuscitation 2013;84:85-92.

26. Skorning M, Bergrath S, Rörtgen D, et al. Teleconsultation in pre-hospital emergency medical services: real-time telemedical support in a prospective controlled simulation study. Resuscitation 2012;83:626-32.

27. Overdyk FJ, Dowling O, Newman S, et al. Remote video auditing with real-time feedback in an academic surgical suite improves safety and efficiency metrics: a cluster randomised study. BMJ Qual Saf 2016;25:947-53.

28. Branzetti JB, Adedipe AA, Gittinger MJ, et al. Randomised controlled trial to assess the effect of a Just-in-Time training on procedural performance: a proof-of-concept study to address procedural skill decay. BMJ Qual Saf 2017;26:881-91.

29. Zanner R, Wilhelm D, Feussner $\mathrm{H}$, et al. Evaluation of M-AID, a first aid application for mobile phones. Resuscitation 2007;74:487-94.

30. Renshaw J, Eaton G, Gregory P, et al. The BHF PocketCPR smartphone application: 'Staying alive' with bystander CPR. Resuscitation 2017;118:e3-4.

31. Lin Y-Y, Chiang W-C, Hsieh M-J, et al. Quality of audio-assisted versus video-assisted dispatcher-instructed bystander cardiopulmonary resuscitation: a systematic review and meta-analysis. Resuscitation 2018;123:77-85.

32. Beskind $\mathrm{DL}$, Stolz $\mathrm{U}$, Thiede $\mathrm{R}$, et al. Viewing an ultra-brief chest compression only video improves some measures of bystander CPR performance and responsiveness at a mass gathering event. Resuscitation 2017:118:96-100.

33. Salisbury C, O'Cathain A, Thomas C, et al. Telehealth for patients at high risk of cardiovascular disease: pragmatic randomised controlled trial. BMJ 2016;353.

34. Siu LW, Boet S, Borges BCR, et al. High-Fidelity simulation demonstrates the influence of anesthesiologists' age and years from residency on emergency cricothyroidotomy skills. Anesth Analg 2010;111:955-60.

35. Beom JH, Kim MJ, You JS, et al. Evaluation of the quality of cardiopulmonary resuscitation according to vehicle driving pattern, using a virtual reality ambulance driving system: a prospective, crossover, randomised study. BMJ Open 2018;8:e23784.

36. Cooper S, Cant R, Porter J, et al. Rating medical emergency teamwork performance: development of the team emergency assessment measure (team). Resuscitation 2010;81:446-52.

37. Sunde GA, Sandberg M, Lyon R, et al. Hypoxia and hypotension in patients intubated by physician staffed helicopter emergency medical services - a prospective observational multi-centre study. BMC Emerg Med 2017;17:22

38. Pelaccia T, Tardif J, Triby E, et al. From context comes expertise: how do expert emergency physicians use their know-who to make decisions? Ann Emerg Med 2016;67:747-51.

39. Oliver GJ, Walter DP, Redmond AD. Prehospital deaths from trauma: are injuries survivable and do bystanders help? Injury 2017;48:985-91.

40. Bray J, Case R, Cartledge S, et al. Barriers to bystander cardiopulmonary resuscitation (CPR) in a dispatcher CPR system: a qualitative review of emergency calls. Resuscitation 2017;118:90.

41. Pollack RA, Brown SP, Rea T, et al. Impact of bystander automated external defibrillator use on survival and functional outcomes in shockable observed public cardiac arrests. Circulation 2018;137:2104-13. 